Boise State University

ScholarWorks

4-1-2004

\title{
Conversational Performance and the Poetic Construction of an Ideology
}

Gail Shuck

Boise State University 


\title{
Conversational performance and the poetic construction of an ideology
}

\author{
G A I L S H U K \\ Department of English \\ Boise State University \\ Boise, ID 83725 \\ gshuck@boisestate.edu
}

A B S T R AC T

This study places conversational performance, or speakers' attempts during everyday talk to draw attention to the aesthetic form of their utterances, at the center of an analysis of linguistic ideology. It examines, in particular, the ways in which two white, middle-class, U.S. university students use performance strategies to construct as Other an English-speaking man whom one student encounters on a flight from Saudi Arabia. Drawing on a socially and ideologically situated theory of verbal art, this article proposes five interconnected relations between performance and ideology. Together, these relations constitute a step toward an integrated theory of an inextricable link between the ideological structure of performance and the potential for performance in ideological discourse. (Oral performance, linguistic ideology, nonnative speaker, ideological discourse, verbal interaction, young adult discourse, verbal art in conversation)*

\section{N T R O D U C T I O N}

The relationship between texts and the contexts in which they are produced can be illuminated by an agent-centered, practice-oriented study of performance (Bauman 1977, 1986, 1992; Bauman \& Briggs 1990; Limón 1982; Briggs 1988, 1996, 1998; Haviland 1996; Wilce 1998). From such a perspective, we can examine the interactional processes by which performers and audience members frame their words to shape new contexts. Performances are framed as distinct from the rest of an interaction and worthy of special attention (Bauman 1977, Bauman \& Briggs 1990, Shuck 2001). This is true in everyday conversations as well as in more clearly bounded, culturally recognized forms of verbal art. Performers' strategies for gaining and maintaining attention, such as repetition, dialogue, rhythm, expressive phonology, and even laughter, have an impact on the content of their performances, rendering such content susceptible to sometimes dramatic transformation. An individual's creative contributions to a given text allow propositions to be molded, stretched, and ultimately accepted as true. The role of the individual performer - combined with listener 
participation in a performance - is thus critical to participants' interpretations not only of the speech event at hand but also of the ideological discourse that emerges from it.

The present study is an analysis of a single narrative, retold in immediate succession multiple times, about an adolescent girl's encounter with a "foreign"sounding man sitting next to her on an airplane. The story emerged during a one-hour interview that I recorded in 1997 as part of a larger study examining native English speakers' ways of speaking about nonnative speakers and their language use (Shuck 2001). The primary performer was one of 52 undergraduate students at a large southwestern U.S. university whom I interviewed in pairs or groups of three (21 interviews total) over the period from spring 1997 to spring 1998. Questions dealt with school-related subjects such as experiences with teachers, courses, and classmates, and with more specifically language-related subjects such as experiences learning one or more languages or interacting with mono- or multilingual speakers (depending on the linguistic background of the interviewee). The study identified a relatively stable, coherent ideology of language, which I am calling the IDEOLOGY OF NATIVENESS, that constructs the category 'native English speakers' as contiguous with Americans (and sometimes British), and 'nonnative English speakers' as contiguous with foreigners. ${ }^{1}$ Whether in the speech of monolingual, U.S.-born, English-speaking students or multilingual, international students (less so among multilingual U.S. residents or citizens), this Us/Them division of the linguistic world is located in discourses such as claims that accents are incomprehensible, complaints about immigrants who do not learn "the language," and an apparent cultural ambivalence toward learning "foreign" languages. At the core of this ideological model is a view of the world as naturally monolingual (Silverstein 1987, Blommaert \& Verschueren 1992, Gal \& Irvine 1995, Shuck 2001).

This monolingualist model was intricately connected in these interviews to instances of performative speech, such that the performers - and usually their audiences - participated in a patterned, collective defining of native and nonnative speakers, exaggerating differences between 'us' and 'them'. In many interviews, for example, questions about good and bad teachers led students to construct dramatic complaints about instructors with "incomprehensible" accents - complaints that often included exaggerated representations of the instructors' voices and claims that one "couldn't understand a word he/she said." As we shall see in the performance analyzed here, the primary performer, aided by one of her listeners, draws on the ideology of nativeness to construct the man on the plane as foreign, incomprehensible, and even frightening. The role of performance in construing relations between language use, on one hand, and ethnicity, identity, nationality, and even morality and intelligence on the other, is particularly critical because such performances, and bits of performances, can easily become part of a collective, hegemonic understanding of a linguistic and social order (Shuck 2001). 
During the sixth interview in the study, three students - all white, U.S.-born, native English speakers (two female [F9, F10] and one male [M3]) - were discussing their international experiences when I asked a direct question about whether they had talked with, as I put it in that interview, people who "didn't speak English very well." Such questions often elicited complaints, a result that I had anticipated to some degree. However, the extent to which those complaints were dramatized and exaggerated was completely unexpected. The primary performer (F10) of this narrative (ex. 1) responds to my question at first with a brief story about a man on a plane from Saudi Arabia to the U.S. who had started talking to her and, in doing so, apparently frightened her. Immediately following a challenge from me regarding her claims of fear (line 27), she retells it more dramatically. One of her discussion partners (F9) then makes a contribution (53-72) to the renewed performance - a contribution that does more than merely confirm the storyteller's characterization of the English speaker. It extends it, adding further negative components to an already negative representation. The entire narrative is reproduced below: ${ }^{2}$

(1) The "murderer"-on-the-plane story

1 G: have. either of you ever. been in a conversation with somebody who spoke

2 English-

2 ..n-..in a sense that-

$3 \quad$...well,

$4 \quad$... who didn't speak English very well,

5 in your. .estimation?

6 F10: ...like recently?

7 G: ..ever.

F10: ...yeah,

9 when we were flying back over,

10 from Saudi Arabia,

11 this is really sad.

12 my mother left us,

13 ...we-

14 it was like a-

15 we sat like in the no smoking section,

16 and she met this guy named (Ali? Dali?),

17 or whatever,

18 he's a good friend of the family's now,

19 but,

$20 \quad \ldots$ and I woke up,

21 and he was like sitting there on the plane,

22 and he was trying to talk to me,

23 and I was just li:ke,

$24 \quad$ OK whatever,

25 and I got scared,

26 and I switched seats with my brother 〈[fast and low] so I couldn't talk to him anymore.[fast] $\rangle$

27 G: $\quad . .\langle @$ why'd you get scared. @ $\rangle=$

28 F10: = cause I couldn't understand him! 


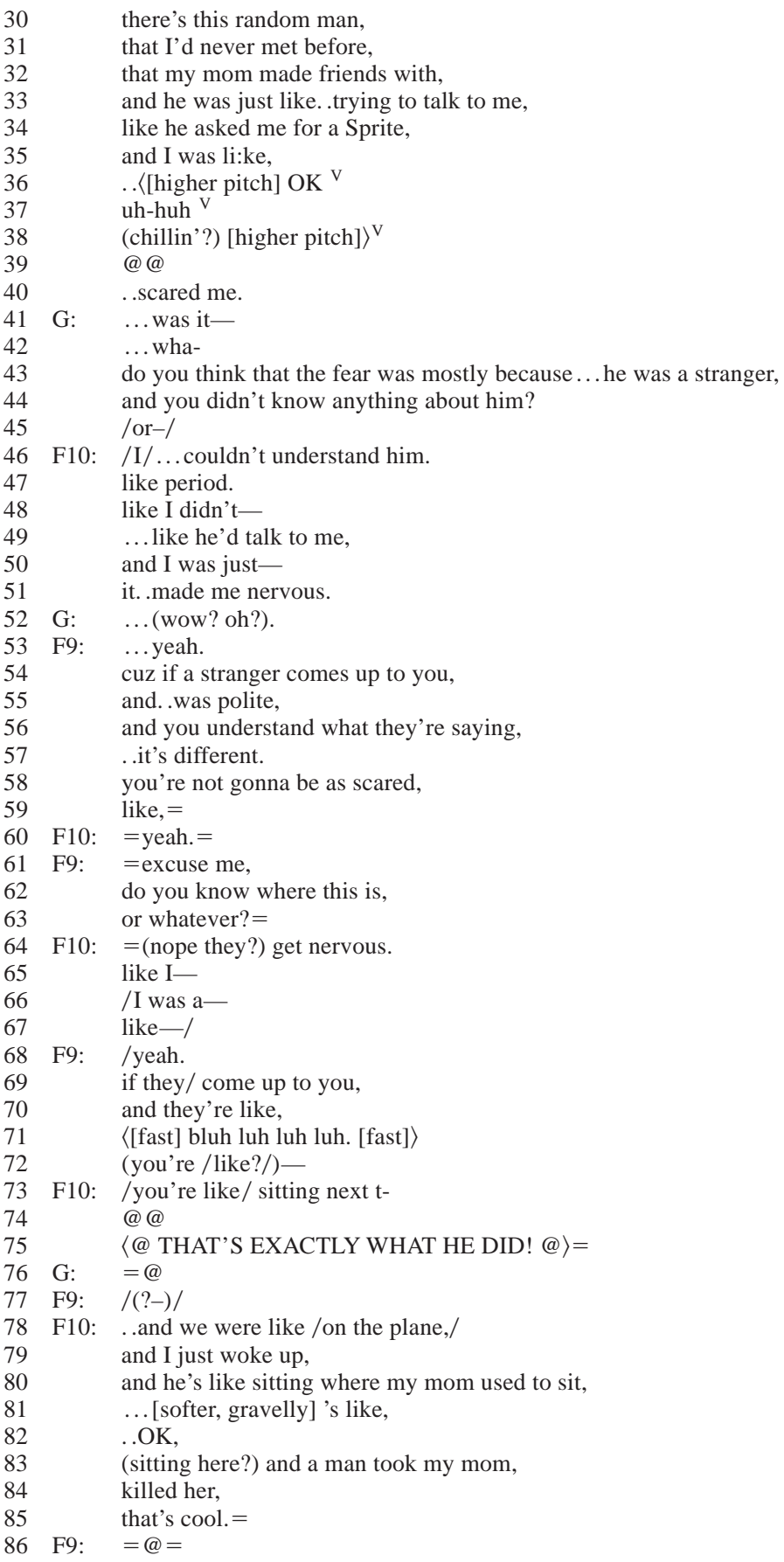

there's this random man,

that I'd never met before,

that my mom made friends with,

and he was just like. .trying to talk to me,

like he asked me for a Sprite,

and I was li:ke,

.. ([higher pitch] OK V

uh-huh $\mathrm{V}$

(chillin'?) [higher pitch] $\rangle^{\mathrm{V}}$

@@

G: $\quad$...was it-

... wha-

do you think that the fear was mostly because... he was a stranger, and you didn't know anything about him?

/or-/

F10: /I/ ... couldn't understand him.

like period.

like I didn't-

... like he'd talk to me,

and I was just-

it. .made me nervous.

G: $\quad$... (wow? oh?).

F9: ...yeah.

cuz if a stranger comes up to you,

and. .was polite,

and you understand what they're saying,

..it's different.

you're not gonna be as scared,

like, $=$

F10: =yeah. $=$

F9: =excuse me,

do you know where this is,

or whatever? =

F10: = (nope they?) get nervous.

like I-

/I was a-

like-1

F9: /yeah.

if they/ come up to you,

and they're like,

$\langle[$ fast] bluh luh luh luh. [fast] $\rangle$

(you're /like?/)-

F10: /you're like/ sitting next t-

@@

$\mathrm{G}: \quad=@$

F9: /(?-)/

F10: . .and we were like /on the plane,/

and I just woke up,

and he's like sitting where my mom used to sit, ... [softer, gravelly] 's like,

. .OK,

(sitting here?) and a man took my mom,

killed her,

F9: $=@=$ 
87 G: $=$ tsh. $=$

88 M3: $=$ [exhaled] ${ }^{\prime} \mathrm{h}=$

89 F10: $=$ I'll sit by him on the plane if I want ${ }^{\mathrm{V}}$

90 G: ...〈@ [exhaled] 'h @ $\rangle$

By itself, the image of this man that we glean from this performance makes it worthy of examination for its encapsulation of the ideology of nativeness and its construction of the incomprehensible Other. More than that, this narrative illustrates a particularly complex relationship between performance and ideology in general, consisting in the five relations discussed below. While this narrative alone amply demonstrates these relations, excerpts from other interviews from the larger study will be used to show their pervasiveness and to shed additional light on the framework being developed here. The larger study included interviews with nonnative English speakers as well as with students for whom the native/nonnative distinction was troubling. The present study, however, includes excerpts only from interviews with self-identified native English speakers.

IDEOLOGY IN PERFORMANCE AND THE PERFORMANCE

OF IDEOLOGY

The central claim of this study is that speakers perform ideologies; they do not merely carry their beliefs around unaltered and let them leak out in moments of unmonitored indiscretion. As is the case with the "murderer"-on-the-plane story, dominant ideologies are often central to attempts at verbal art. Indeed, as Sherzer 1987 points out, it is particularly in verbal art that we see the most sharply focused expressions and constructions of the language-culture-society relationship, including dominant beliefs about a linguistic order. Just as performance plays a key role in the construction of ideologies, so do ideologies play a role in the construction of performances. Ideologies inform speakers' choices about the topics of conversation to be performed - that is, the "performability" of particular ideological propositions - and about the discursive patterns that shape the form of the performance.

The bidirectional nature of this relationship between performance and ideology can be captured in at least the following five basic relations, which together highlight the tension between the prior and the emergent, the fixed and the novel (Becker 1979, Tannen 1989). To shed light on this tension, it is critical that we examine the discursive minutiae ${ }^{3}$ of both the performances and their connections to the surrounding discourse. As this analysis will reveal, a single performance may be linked with ideology in most or all of these ways simultaneously:

1. Performances index existing ideological models.

2. The relatively limited set of discourse patterns (metaphors, themes, narratives, argument strategies, etc.) entailed by a given ideology are readily available, and are drawn upon, as resources for aesthetic displays. 
3. The framing of talk as performance opens up a discursive space for constructing ideological extremes and stereotypes and, more important, for momentarily rendering them acceptable.

4. The collaboration that performances invite creates opportunities for the proliferation of ideological extremes.

5. Performances' capacity for recontextualization allows ideologies to be shaped by greater numbers of speakers and therefore to be subjected to multiple transformations.

Relations 1 and 2 focus on the relative stability of ideology and indicate its use as a resource. That is, ideology provides the basis in both content (relation 1) and form (relation 2) for a given performance. Both of these relations posit ideology as a network of meanings that exists in some relatively stable form, with relatively stable discourse structures associated with it. However, relation 1, the relation of indexicality, also points to the "context-bearing features" (Ochs 1990:288) of performance. In indexing those existing ideological models, performances have the capacity to shape participants' understanding of their respective social and political positions. Relation 1, then, has as much to do with performance's dynamic, active role in shifting participants' interpretation of the interactional and cultural context as it does with ideology's role as a relatively static feature of that context.

Claims that performances are informed by ideological models have been made by Limón 1982, Bowen 1989, Briggs 1998, Wilce 1998, and Kroskrity 1999. However, it is in the converse relation - the role of performance in constructing ideologies - that this study makes a novel contribution to both performance studies and studies of ideology in discourse. Relations 3, 4, and 5 focus primarily on the construction of ideologies during performative talk and suggest a conceptualization of ideology as dynamic and fluid. ${ }^{4}$ During a performance, speakers can transform ideological premises toward extremes or inscribe them in particularly memorable, poetic ways. Those performances generate opportunities for subsequent performances by other speakers and for reanimating old performances in new contexts, thereby increasing the likelihood that transformed ideological propositions will become part of an ever-expanding network of beliefs. Each of these five relations will be discussed in detail below.

\section{Relation 1: Performances index existing ideological models}

Performances index and depend on the stability of ideological models, while providing opportunities for sudden shifts in ideological position as well as for transformations of those models. These models form part of the ideological context to which speakers orient themselves as they participate in performative as well as nonperformative discourse. Particular utterances index that context, in that they presuppose ideological worlds in which certain propositions are taken at least by the speaker, but often by the listeners as well - to be true or logical 
(Silverstein 1979, Ochs 1990). Indexicality is thus an important part of the contextualization process; it allows researchers and participants alike to make sense of the interaction as they interpret their relationships with their interlocutors, as well as the ideological positions of those interlocutors.

F10's "murderer"-on-the-plane story indexes the ideology of nativeness, a linguistic ideology that was firmly established in social discursive space by 1997, when this interview took place, and certainly also by the early to mid-1990s, when the narrated event took place. In answering my question about people who "didn't speak English very well," F10 quickly indexes the man's foreignness by adding or whatever after a name she apparently knows now (17). Within this ideology of nativeness, mentioning or implying foreignness is sufficient to establish his status as a nonnative English speaker. This association of one nation with a single language is widely held and has been described by Silverstein 1987, Blommaert \& Verschueren 1992, and Gal \& Irvine 1995. The ideology of nativeness further posits that linguistic nonnativeness makes one incomprehensible. 'Native' and 'nonnative' are rendered dichotomous, mutually exclusive categories in this discourse. This means that, even if speakers do not use these terms in particular, they exaggerate differences between their own speech - taken to be normal and unremarkable - and the speech of others. In the talk of most international students, even those from countries such as India or Singapore in which English is a primary language, this dichotomous model of the linguistic world appears in, among other discourses, self-denigrating talk of a lack of English proficiency. In the talk of U.S.-born, native English speakers, it appears most clearly in complaints about incomprehensible accents.

Although F10's first telling of the narrative draws on this model of nonnative speakers' linguistic ineptitude and explicitly claims that she was afraid, she has not (at least by line 26) directly argued that it was the man's incomprehensibility that made him frightening. Her emphatic response to my question about why she got scared (28), however, clearly shows that the truth of that proposition should have been obvious. She explains, 'Cause I couldn't understand him! That line reveals her annoyance at having to explain the connection between the man's nonnativeness and her fear. This connection is further highlighted throughout the performance with two additional utterances of scared (40 and 58, the latter uttered by her partner) and two of nervous (51 and 64).

In order for the suggestion of fear to make sense to her listeners in this context, there must exist an ideology that equates foreignness with fear in public discourse. Indeed, F10 seemed to find it easy to draw on xenophobic tendencies in the United States, which were available in public discourse long before September 11, 2001. Inda 2000 analyzes the discourse supporting California's Proposition 187, passed in 1994, and finds a pervasive construction of immigrants as parasites who threaten the social, cultural, linguistic, and economic well-being of the nation. Jaret 1999 similarly notes a heightened fear of foreigners in the last two decades of the 20th century. This xenophobia has long influenced U.S. film 
and television conventions, which portray nonwhites and/or non-Americans as "bad guys" and link nonstandard or foreign accents with negative - or at least bumbling or humorous - character traits (Lippi-Green 1997). Linking language use with national origin allows speakers like F10 to project a fear of foreigners onto perceived nonstandard language use to produce a fear of linguistic Otherness. The notion of a "standard," in the "aggressively hegemonic," emblematic sense which Silverstein describes (1987:286), undergirds F10's naturalized assumption that incomprehensibility and foreignness (and probably also maleness) added together equal threat. ${ }^{5}$

F10's indexing of the ideology of nativeness is clear in her momentary assertion of the man's inability to communicate at all in English. Such a rejection of any linguistic competence on the part of the Other is widespread and is often encoded in a variant of this claim: "[I/You] couldn't understand a word [he/she/ they] said" (Shuck 2001). This categorical rejection is invoked in F10's answer, 'Cause I didn't understand him! Although she reconstructed something he had said (he asked me for a Sprite), she later reiterated the claim of incomprehensibility: I . . couldn't understand him. Like period (46-47). Moreover, when one of her interview partners, F9, represented the man's voice as wordless blather - bluh luh luh luh - F10 agreed with her characterization. Such representations are part of a discourse of exclusion, by which only native speakers of English - indeed, only native speakers of certain varieties of English - are admitted as comprehensible, unremarkable members of the community of English speakers. These patterns are relatively stable, accessible, and pervasive, akin to what Bakhtin 1981 might call authoritative discourses that have become assimilated into our ideological consciousness as "internally persuasive discourse" (1981:342-48). They are accepted uncritically as true, at least at the moment of their utterance, and are reanimated in new contexts as though they were originally conceived. (The truth value of these internally persuasive discourses is addressed in greater detail under relation 3.) The creation of this performance, then, depends on the prior existence of an ideological model that provides the speaker with performable themes and linguistic patterns. Moreover, as we shall see in the next section, the relative stability of these patterns allows them to serve as resources for aesthetic transformation in conversational performances.

Relation 2: The set of discourse patterns entailed by a given ideology are readily available, and are drawn upon, as resources for aesthetic displays

Any ideological model produces limited sets of formulaically encoded themes and arguments (Silverstein 1987, Woolard 1989, Hill 1992). This stability makes them readily available for use in verbal interaction. Fixed, or at least moderately formulaic, patterns associated with particular topics are a linguistic resource upon which speakers draw, not only to find the words to make their points but also to make those points in aesthetically interesting ways. The central connection between performance and certain ideological positions has to do precisely with the 
easy accessibility of discourse patterns associated with those positions. Patterns such as "[I] couldn't understand a word [they] said," are so readily available that speakers seem to find them hard to avoid, even when the same speakers primarily take ideological positions that contradict the beliefs encoded in those forms (Shuck 2001).

Once we understand the ease with which certain discourse patterns can be accessed by any speaker, we can begin to see how such patterns are used as linguistic resources in performative talk. In most of the interviews in this study, the emergence of certain topics seemed to invite performances, particularly complaint performances: poor instructors, purposeless assignments, unfair grading practices, lazy foreigners, and incomprehensible accents. Within those performances, speakers not only employed fixed phrases; they also poetically transformed them in novel ways. Speakers' reliance on such patterns as resources for aesthetic display is critical to a study of performance because it allows us to examine the human potential for creativity and for "the play of familiar patterns" (Tannen 1989:13). Indeed, the tension between the familiar and the novel provides a foundation not only for the creation of a given performance but also for its acceptance by the audience As a performance.

The incomprehensible accent complaint, one of the most common types of performance in my interviews, illustrates this use of ideological discourse patterns as an aesthetic resource. As I mentioned earlier, this complaint has as a primary component the canonical form, "I/You/We couldn't understand a word he/she/they said." That sentence, along with variations such as "I couldn't understand a thing," appeared more than 30 times in nine different interviews. Its prevalence in U.S. discourse practices makes it especially available for aesthetic transformation, as in (2), from another interview:

(2) Aesthetic transformation of a canonical form

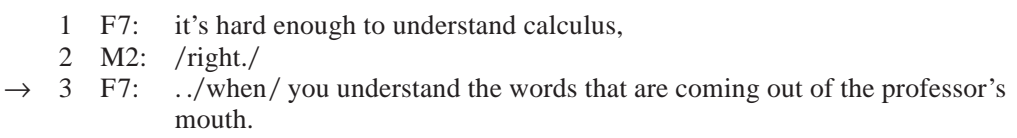

This image - words coming out of one's mouth - is a clear instance of a poetic transformation of a relatively fixed phrase. A less poetic alternative might simply have been "understand what he's saying." Instead, F7 chose to provide a much more visceral, visual image. The available pattern, then, became a resource for conversational artistry as well as a moment of participation in the same ideological discourse constructed by the narrator of the "murderer"-on-the-plane story. In that story, the canonical pattern, "I couldn't understand a word he said," underlies two utterances in particular. First, it is directly indexed by F10's exclamation 'Cause I couldn't understand him! (28). She reiterates the point after my second attempt (41-45) to get her to elaborate on the connection between her fear and his being a nonnative speaker: 
(3) Rejection of language proficiency

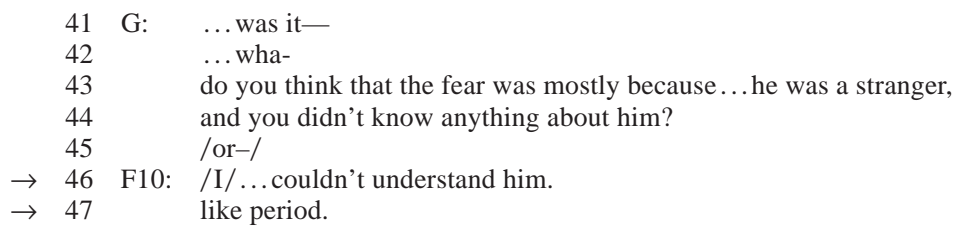

Rather than offering further explanation of that connection, she resorts to a variant of the canonical rejection of the foreigner's language proficiency, "I couldn't understand a word he said."

To help F10 answer my question about why she was afraid, her partner, F9, suggests in lines 54-57 that the man was rude as well as incomprehensible (see relation 5, below, for an analysis of the recontextualization that facilitates such transformations of the antagonist's character). F9 then offers her own dramatic representation of the voice of incomprehensibility: a rapid, machine-gun-like bluh luh luh luh (71). Again, this distorted representation depends on the speaker's easy access to the relatively stable notion that nonnative speakers' uses of English are incomprehensible.

A similarly fixed phrase that appeared several times in my data is "We're in America," in reference to the use of a language other than English. This trope, along with its variants "This is America" and "I'm/You're in America," indexes a simplistic ideological equating of English and America, which finds easy entry into a complaint performance about nonnative English speakers in the United States. The following example is taken from an interview with a particularly progressive female student, F6, who expressed interest in other languages and cultures, had had a Palestinian boyfriend, and was among the only students to raise without criticism or lament the possibility that some Americans do not speak English. Her use of we're in America thus came as a surprise, although she and her partner had already been discussing exclusion from a conversation because of the use of a particular language, a discussion about which she had said she had "mixed feelings." In this excerpt from that interview, she is talking about a Polish friend of hers in the United States. To indicate her sudden shift of position, I have italicized the multilingualist arguments and underlined the monolingualist ones (ignoring for the moment the role of but, just, etc., in constructing a merely concessionary position within a primarily monolingualist argument):

(4) F6's monolingualism

1 F6: . .like. .her mom would come into the room and starting speaking to her in Polish.

2 and they BOTH speak English,

3 just fine,

$4 \quad$... and-

$5 \quad$... it was just like-

6 ..I I knew they weren't talking about me,

7 Imean, 


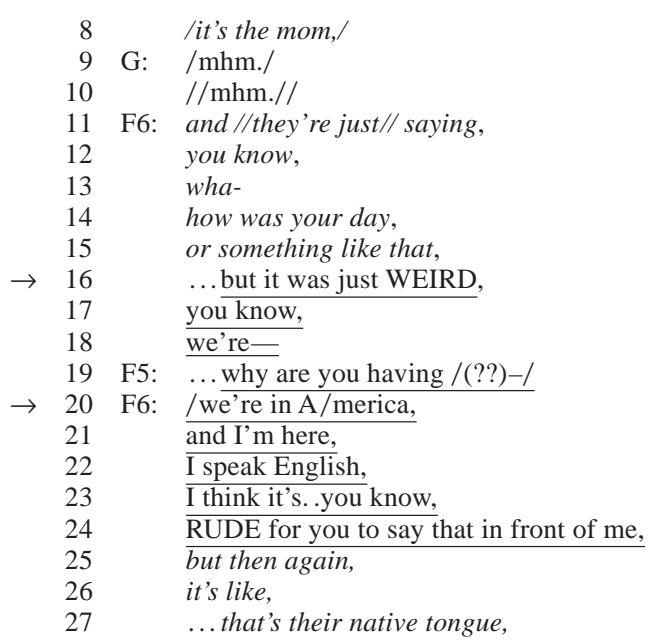

F6 begins with an acknowledgment of the naturalness of the friend's mother's speaking Polish, but at line 16, her speech becomes more involved and dramatic. By line 20, she has fully - albeit momentarily - shifted allegiances, from a more inclusive, multilingualist position to a monolingualist position. Her seemingly sudden use of the trope we're in America can be explained by its accessibility and, by extension, its performability. She seems almost destined to draw on that ideology once she begins to paint an emotional picture of her own linguistic exclusion. ${ }^{6}$

Indeed, the performativity of this segment heightens at the moment she says WEIRD, simultaneously marking a shift in ideological position and an opening of a performative frame that makes the overtly monolingualist ideology more acceptable (see relation 3 regarding the framing of acceptability). That F5 perceives the shift to a more performative frame may be evident in her unfinished line Why are you having...? Although it is not possible to confirm this, F5 may have been relying on the same perspective-taking strategy she frequently used throughout the interview, constructing the thoughts of the narrative's main character at the time of the narrated event. I interpret her truncated utterance as the beginning of a question like this: "Why are you having this conversation in Polish in front of me?" If this is true, F5 uses the second person pronoun in this question to address the mother and daughter in F6's story, animating F6's voice at the time of the recounted event, rather than using you to refer to the F6 who is currently speaking. If indeed this is what she is doing, she participates in the performance begun by F6, defining conversational rules according to a monoglot ideology. Regardless of F5's intent, F6 makes that ideology explicit as she completes her previously truncated line we're in America. She continues the performance, employing a similar rhythm and intonational contour in each of the three consecutive intonation units beginning with we're in America: 
(5) "We're in America"

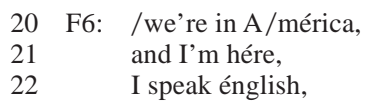

Here, the formulaic phrase itself is not transformed; rather, it provides an opportunity to perform and indeed marks a shift into a performance frame, a shift that F5 seems to have noticed as well. That this commonly heard trope comes so soon after the performance frame is entered is no coincidence. It is, instead, a fairly predictable result of the relationship between performance and ideological elements that are already floating around in social discursive space. The fixity of those elements allows them to be used as raisons d'être for performances because they provide common ground for speakers and listeners, on which novel uses of these patterns can be constructed.

Relation 3: The framing of talk as performance opens up a discursive space for constructing ideological extremes and stereotypes and, more importantly, for momentarily rendering them acceptable

So far, we have examined relations between performance and ideology that assume the prior existence of ideological models. A given performance indexes relatively stable, presupposed components of those models; and certain discourse patterns produced by those models, such as variations of "You can't understand a word he says" or "We're in America," allow speakers a degree of discursive pre-patterning that provides opportunities for conversational creativity. Supported by that fixity, speakers rely on what they know about performance - their performative competence - to negotiate the tension between the fixed and the novel.

Let us now examine the other half of this tension: the novel, the emergent, the discursively constructed elements constituted by the interaction itself. Performance plays a central role in that construction. As I will demonstrate in this and the following two sections, the framing of talk as a performance provides contextualization cues to participants to help them make sense of what is being performed. First, it shapes norms for interpreting the social acceptability or truth value of the performed claims, and it can move ideological boundaries toward the extreme or the remarkable, thereby shaping the ideological model in participants' consciousness to some degree. Second, performance shapes the interactional context such that co-performances or successive individual performances are acceptable and even expected. Third, performances can be recontextualized, increasing the number of people who can reanimate the ideologies embedded in them.

The notion of FRAME, as developed by Bateson 1972, Goffman 1974, Tannen 1979, and Tannen \& Wallat 1993, is fundamental to our understanding of the poetic license that performers take as they create particularly exaggerated representations of others' talk. Framing devices in conversational performance, such as repetition, openings and closings, and rhythm, set a display apart from the rest 
of the interaction, drawing attention to the form in which the communication occurs. Talk framed as a performance commands special attention and, ultimately, some kind of evaluation from the audience. Because listeners pay heightened attention to performed ideological positions, framing plays a critical role in shaping the norms for interpreting social truths. A shift into a performance frame tells us that it is socially acceptable to sacrifice accuracy, grammaticality, politeness, and so on for the sake of a performance. ${ }^{7}$

An obvious example of the framing of social acceptability can be found in one student's discussion (6) of the benefits of an international first-year composition class, English 107. The student ignores social norms for avoiding racist terms and, without commentary or irony, uses the word Chinaman, which conveniently ends with the same schwa $+\mathrm{n}$ ending as German and Mexican:

(6) Violating social norms for art's sake

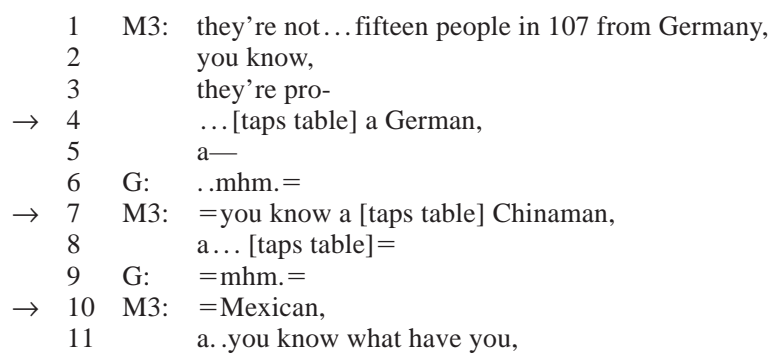

His saying Chinaman surprised not only me but also a number of students in later interviews who listened to this recording. This student is clearly more interested in the poetry of having three noun phrases all end with -an than in the implications of the word Chinaman. ${ }^{8}$ That poetry is enhanced by his tapping the table upon uttering each noun and by the identical rising intonational contour at the ends of those three lines (4, 7, and 10). Although I did not challenge him on his choice at the time, perhaps because of the very same shift in expectations engendered by the performance, I am confident that he was at some level conscious of the pejorative nature of Chinaman. However, once his attempt at a slightly poetic turn begins, at the first table-tap, he brushes off social expectations in favor of performative ones. As long as the audience accepts it, a performer can generate a reality that might be rejected in less performative talk.

This reality, at least at the moment of the utterance, is naturalized for the participants, such that the iconic association of an ethnic term with what is thought to be a bounded, identifiable social group is considered natural and unworthy of comment (Gal \& Irvine 1995). This naturalization process is particularly evident in claims of the total incomprehensibility of others' accents. Once speakers are performing, Grice's (1975) Maxim of Quality becomes quite malleable, if not altogether irrelevant. Kroskrity's (1992) discussion of non-kiva innovations of Arizona Tewa kiva speech illustrates the possibilities for shifting or suspending 
norms for interpretation once a performance frame has been invoked. F9's rapidfire bluh luh luh luh takes advantage of such possibilities. A remarkably similar trivialization of the voice of the incomprehensible Other came from a different interview (7). The student, F1, began by complaining that she did not understand a WORD [her history professor] said. She then added this characterization:

(7) The voice of the Other

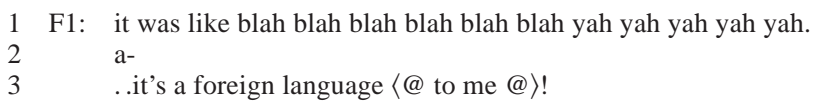

Her attempt to perform overrides any expectation that her imitation be the least bit realistic. Such an absurd, derogatory imitation creates a new truth, a new norm for social acceptability. No one challenges the truth value of either of these students' claims. Indeed, F10, on hearing F9's bluh luh luh luh, goes so far as to claim, That's exactly what he did, explicitly confirming the truth of the representation. Because the notion of the incomprehensible foreigner already exists in the ideological model, such imitations fall within the range of what might count as an accurate representation within that model. Moreover, the performance frames in which these utterances occur virtually eliminate the truth constraints that might otherwise apply to non-performative discourse.

This is precisely how performance is simultaneously presupposed by and constitutive of ideology. Such an extreme representation of another's accent in English as equivalent to "a foreign language" is possible only if the ideological discourse already supports the premise that foreign accents are incomprehensible. The extreme then becomes part of the ideology at the moment of its performance. Its vividness - its particularity (Becker 1984) - reifies the incomprehensible foreigner for the audience. The performance further establishes a context in which nonnative English speakers are classed as others and subject to derision. This further creates contextual conditions that allow for the derision of other Others; in the interview with F1 (7) and her partner, those also included American Indians, authors who write about the beauty of the desert, and people who keep quiet during class discussion even if they disagree, namely the one Hispanic student in an English class full of Anglo students. Talk that is framed as performance places all these Others on the same contrasting level in a taxonomy of the human world: bad teachers, people with accents, myopic writers, taciturn students, and American Indians are thus rendered equivalent and therefore subject to equal, and socially acceptable, degrees of ridicule. Although non-performative talk may similarly render disparate groups or phenomena equivalent, performance frames in particular provide a kind of safety that makes such comparisons less likely to be challenged.

The contextualization cues in the "murderer"-on-the-plane story enable a particularly offensive transformation of truth, beyond the simple claims of the man's incomprehensibility. Together, the two performers take the canonical image of 
the incomprehensible foreigner and embellish it until it is acceptable to think that this nonnative English speaker, merely by virtue of his nonnativeness, is dangerous.

By the middle of the first telling, F10 has claimed that the main character was scary. This can be seen as the first of three transformations of his character. With F9's performative contribution, he becomes rude as well (8). F9 attempts her own answer to my question about the connection between fear and incomprehensibility by suggesting, without apparent irony, that the man must not have been polite, although she knew little more about his behavior than that he tried to talk to F10 and asked her for (or possibly asked if she wanted) a Sprite:

(8) The transformation to rudeness

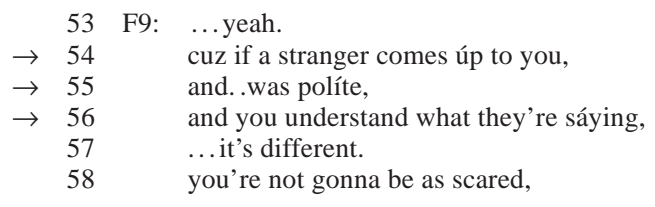

F9 contributes to the collective performance with some intonational and rhythmical parallelism in 54-56, in which the intonational contours end on approximately the same pitch. This rhythm sets up the next phase of her performance, in which she contrasts a hypothetical polite, comprehensible stranger with the rude, incomprehensible stranger she imagines the man to be:

(9) The hypothetical stranger

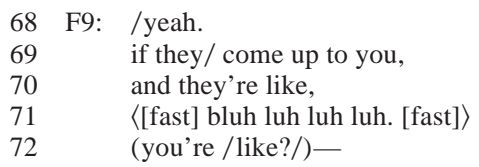

The second major transformation of the man's character - from nonnative speaker to frightening nonnative speaker to rude, frightening nonnative speaker - is now complete.

Finally, encouraged by this positive response from F9, F10 underscores the message that foreigners with incomprehensible accents are scary by transforming the man from 'scary, rude foreigner' to 'murderer':

(10) The third transformation

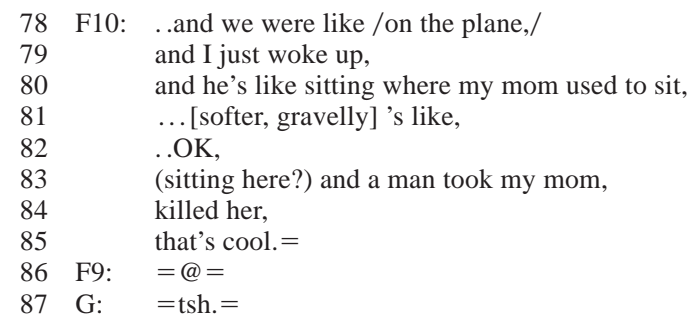


88 M3: $=$ [exhaled] $\mathrm{h}=$

89 F10: = I'll sit by him on the plane if I want $\mathrm{V}$

90 G: ...〈@ [exhaled] 'h @ $\rangle$

Although the responses that follow her performance (86-90) might be interpreted as signs of embarrassment or disbelief, it is not likely that F10 has fallen over the edge of an ideological, performative precipice. Within an ideology that easily supports fear of nonnative English speakers, and within a performance frame that encourages the construction of extreme or absurd representations, the notion that this man might be a murderer is not an enormous leap.

It is this last transformation that directly connects this ideology to a more widespread anti-Arab racism, heightened in the period following the hijackings on September 11, 2001. In this narrative, the "foreigner" is on a plane to the United States from Saudi Arabia and has a name that F10 regards as foreign. At the end of the narrative, F10's quiet utterance represents what she thought when she woke up and found herself sitting next to him: This foreigner, whom she could not understand, took [her] mom [and] killed her. We must not dismiss this simply as an absurd exaggeration that is meant to enhance her performance. The ideological construction of the racialized Other underlies the same fears that allowed Arab, Pakistani, and other nonwhite passengers to be ordered off of U.S. flights following the attacks and that have resulted in the detaining without charge of hundreds of nonwhite immigrants (American Civil Liberties Union 2002, CBS News 2002). It is particularly significant that the fear expressed in this performance - and indeed, F10's suggestion that the man could have been a murderer - arises in direct relation to a question about language. Linguistic otherness is associated with ethnic otherness, and both are associated with fear. In recent years, the widespread association of Arabs in particular with terrorism, made more intense since September 11, 2001 but existing long before that (Shaheen 2001), increases the possibility that an Arab man in particular would be constructed as dangerous. ${ }^{9}$ During performances, exaggerated representations of linguistic, cultural, ethnic, and social boundaries prevail, reifying categories and justifying for the participants the fear associated with those categories.

\section{Relation 4: The collaboration that performances invite create opportunities for the proliferation of ideological extremes}

The capacity to create ideological extremes lies not just in the attempts at drama in a given performance. It also lies within the fundamentally dialogic nature of conversational performance. F10 is unquestionably the primary performer of this narrative, and yet F9's role in the whole performance is critical, particularly in transforming the nonnative English speaker into a rude stranger. Because performance increases involvement in the interaction, it heightens the possibility of shared participation in the making of ideological meaning. Collaboration in performances enables the repetition of ideologically salient discourses and encourages participation in transformations of truth such as the one discussed in the 
previous section. Performances, then, are jointly accomplished and culturally valued means of rationalizing ideological premises in the collective imagination.

This collectivity manifests itself in a number of ways, each of which differs essentially from the others in participant structure (see Philips 1983). (i) Listeners can take minimal turns during and after another participant's performance, usually indicating positive evaluation of both the performance and the performer's ideological position (Yankah 1985). (ii) Speakers can collectively create a performance, whether there are primary and secondary performers or there are equally participatory co-performers. (iii) A successful performance by one speaker effectively invites a subsequent performance by an audience member. It is in the second and third participant structures that we see the greatest potential for joint construction of ideology; these, therefore, will be the focus of analysis in this section.

We have already seen how F9's contribution to F10's man-on-the-plane story encourages F10 to take her performed fear of the presumably nonnative English speaker to a new level. As F9 supplements F10's performance with imagined details about how the stranger spoke, she firmly aligns herself with the ideology of nativeness, particularly with its basic premise that nonnative speakers are incomprehensible. My challenges to F10's claims, however dialogic they may be, elicit only some slightly more specific retellings of the story but do not elicit the transformations that F9 did. In contrast, F9 is able to transform the stranger and get F10 to confirm that new representation of him: That's exactly what he did! F10 explicitly agrees that his speech sounded like gibberish, despite her earlier claim that she understood that he was asking about having a Sprite. The two speakers draw upon each other's claims in order to create a representation of the stranger that was quite different at the end of the performance than at the beginning.

Such co-performances allow speakers and listeners to switch roles in meaningful, well-coordinated, and poetic ways, contributing directly to the interactional organization of the experience (Müller 1992, Erickson 1992, Haviland 1996). They serve two primary purposes. First, they constitute a form of positive audience response. Because my questioning F10's fear clearly did not meet her expectations as a response, F10 did not see it as an opportunity to embellish her story as much as she did after F9's performative contribution. This response, in turn, encouraged further performances with the same theme. Second, the opportunity to jointly create an aesthetic display facilitates the expression of ideological solidarity. In the case of the "murderer"-on-the-plane story, although the two speakers had already expressed ideological solidarity by the time this performance emerged, the collaboration allowed them to confirm the "truth" of this developing representation of the Other.

In some cases, however, speakers who did not consistently express similar positions moved in the direction of ideological unity once they began performing. Such is the case with two other interviewees, one of whom (F6) oscillates between ideological positions frequently during the interview but who largely 
expresses positions of linguistic inclusion rather than exclusion. This is the same student who began a complaint about her own exclusion from conversations between a Polish friend and her mother by claiming we're in America (4). Once again, at the moment her performance begins (see ex. 11), she plants herself in a monolingualist position. Her partner's contributions to her performances, rather than being an opportunity for F6 to argue for her often-expressed, multilingualfriendly views more firmly, only ground F6's utterances more deeply in the dominant monolingualist model.

The two interviewees had been talking both about nonnative English speakers in the United States and about a student exchange trip F6 had taken to Slovakia. In this segment, they jointly decide that obligations to learn a particular language depend on whether one is living in or visiting a country in which that language is dominant. F6 has already suggested that she had felt some degree of obligation to learn Slovak while in Slovakia, saying, If I had the time, I would. However, after she tells a story of being told she should speak Slovak while in Slovakia, and once she and her partner have established an ideological affinity with each other regarding visiting vs. living in foreign countries, her utterances express increasingly monolingualist perspectives. The less performative first half of this segment reveals a considerable degree of ideological solidarity, evident in the degree of lexical echoing (underlined), overlapping speech, and repetition of yeah. In the course of their continued agreement, F6's earlier, albeit limited, sense of obligation to learn Slovak diminishes rapidly until it disappears:

(11) Performance and ideological solidarity

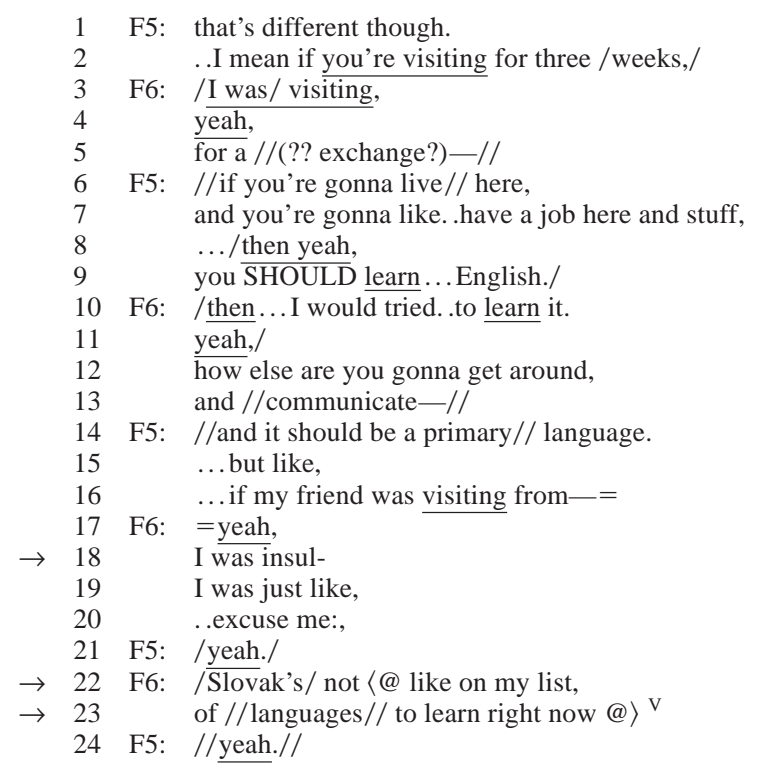


$\rightarrow 25 \quad$ (??) (like?) I know how to say hi,

26 F6: /@/

27 F5: and /that's about it./

As F6 begins performing, with the evaluative opening I was insul[ted], this lack of obligation becomes outright disdain (22-23). F5 contributes to this performance by constructing dialogue as though she were F6, using the first person pronoun and imagining how much Slovak F6 might have known (lines 25 and 27). The two students are now almost bragging about F6's - and, with the deictic shift (25), F5's - not knowing Slovak. ${ }^{10}$ Their collaboratively constructed distinctions between visiting and living in a foreign country - distinctions that I believe they must make in order to sustain a relatively coherent English-only argument - become increasingly clear-cut, leading them to defend F6's lack of proficiency adamantly.

In particularly collaborative co-performances such as this one, speakers move closer to ideological solidarity, in part because the "sanctuary" of the performance frame invites simplified premises and exaggerated representations. Furthermore, performances demand responses, which themselves frequently appear in the form of subsequent performances, such that speakers take turns creating related performances that rely on similar performative strategies and ideological themes. The implied invitation to perform can even result in dramatic contradictions between the ideological stances taken during performative and nonperformative talk (Shuck 2001). Buttny \& Williams 2000 maintain that one performative strategy in particular, reported speech, enables speakers to repeat particularly memorable, quotable words of others. They also suggest that speakers rely on and repeat structured themes, such as discourses of "respect" (see also Hill 1992), as means of establishing their authority in the interaction. My study further suggests that performance frames are especially effective in providing speakers with opportunities to comment on previous performances by drawing on each other's words, thus strengthening ideological cohesiveness.

Relation 5: Performances' capacity for recontextualization allows ideologies to be shaped by greater numbers of speakers and therefore to be subjected to multiple transformations

Because performance frames are actively constructed and because they provide linguistic resources by which listeners interpret talk as performative, they are intricately linked to their immediate situational contexts. However, performances are paradoxically "susceptible to treatment as self-contained, bounded objects separable from their social and cultural contexts of production and reception" (Bauman \& Briggs 1990:72). They can then be reperformed or reported upon or discussed, or otherwise reframed in other contexts. This potential for decontextualization and recontextualization is due in part to the aesthetic effects of certain linguistic elements in a text that create rich textual coherence as well as particular 
connections to audiences and to the rest of the world outside the text (Becker 1984, Tannen 1989, Buttny \& Williams 2000). Because some texts are framed as performances, their aesthetic effects contribute to their memorability, and this helps them to become part of the expressive repertoires of particular listeners/ readers/viewers. Performances, then, forge a link between a discursive past and a discursive present (Becker 1979), and also between that same discursive present and a discursive future, as ideological premises become encoded in a recontextualizable form.

Within the "murderer"-on-the-plane story, the performer herself recontextualizes her own narrative twice, each time heightening the drama of the first telling. In doing so, she moves further and further from an ideological core that characterizes the nonnative speaker as an incomprehensible Other, toward an extreme representation of the nonnative speaker as dangerous enough to be capable of murder. ${ }^{11}$ The first version is reproduced here:

(12) Complete version I

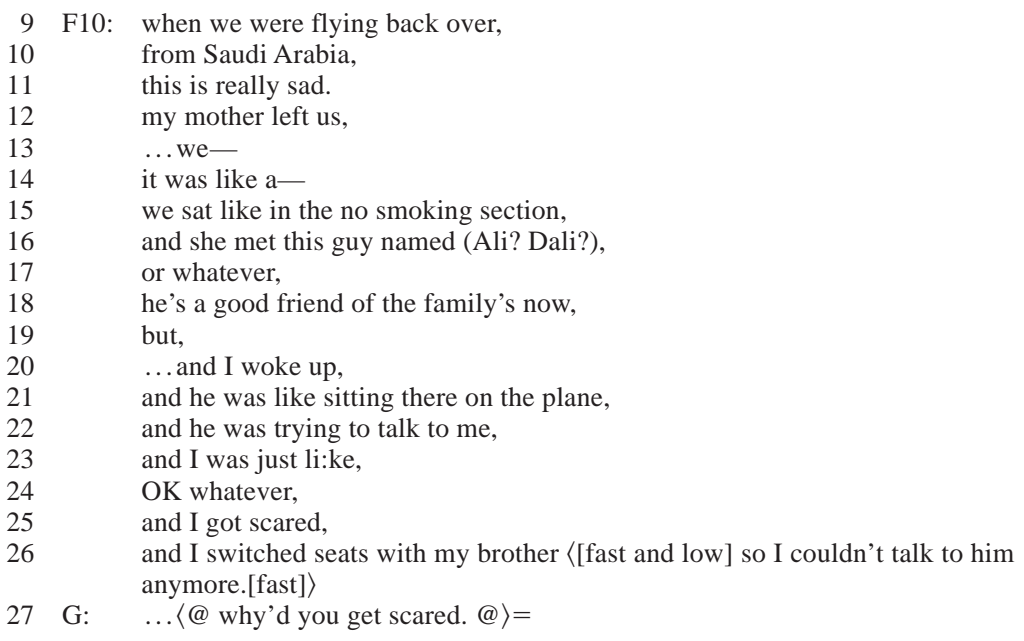

Her next version of the story (13) was apparently sparked by my question in the last line above, Why'd you get scared? In it, she repeats the same narrative event structure as the first version:

1. a man that she didn't know sat next to her (line 30, below);

2. he tried to talk to her (lines 33-34);

3. and she got scared (40).

The new opening (line 28) serves both to answer my question and to offer an external evaluation of the narrative, which attempts to clarify the ideological relationships between fear and a foreigner's accent. Her tone, however, is more dramatic in the new version, starting with the first line (28) and continuing through 
the rhythm of lines 30-32 to the new, more rhythmical version of her reported thought, with two syllables per intonation unit (36-38):

(13) Complete version II

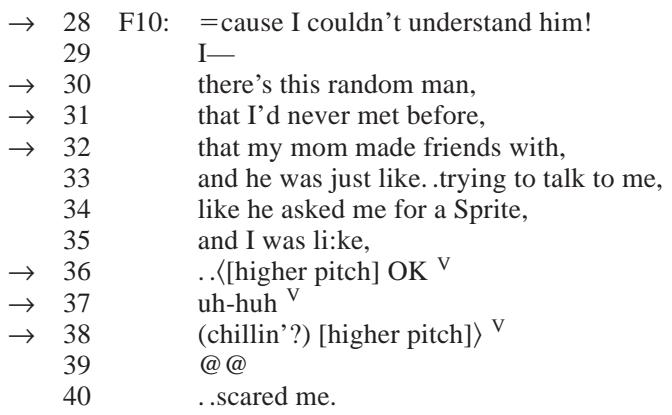

Immediately following this reperformance is my own reframing of my question about what accounted for the fear (ex. 14). She seems to think it is not worth another performance or even an explanation for an interviewer who is apparently missing the point anyway, and so she ends her next turn before letting it develop fully into a performance. She repeats her overall evaluative comment (lines 46-47) and begins another description of the scene (49) but truncates her own utterance (50) before offering her closing statement, a reiterated claim that she was frightened (51):

(14) Truncated version

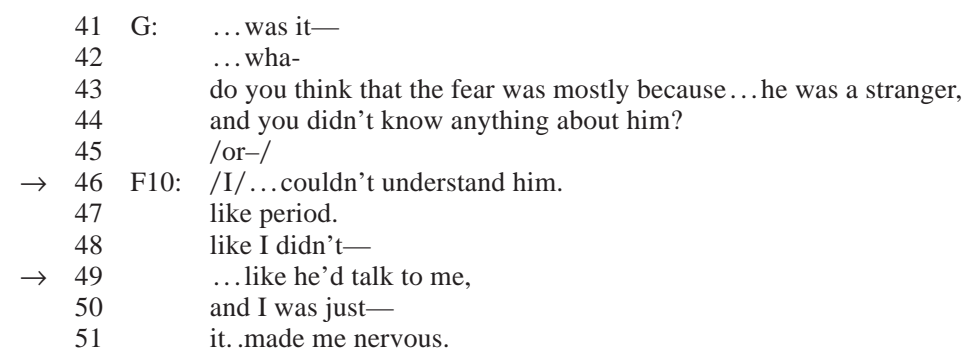

Although she ends this performance abruptly, her interest in performing is renewed when F9 chimes in with her own performance. Indeed, that performance might be seen as a further reframing of F10's narrative (ex. 15). F9 takes the basic narrative propositions (i) that the man talked to F10 (lines 54-56, 61-63, 69-71) and (ii) that F10 got scared (58), and the ideological propositions (i) that he was incomprehensible and (ii) that his incomprehensibility made him scary, and she reframes them in contrast to a hypothetical scenario:

(15) Recontextualization by a listener

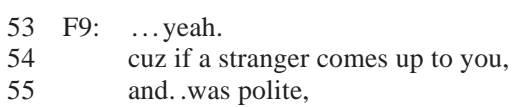




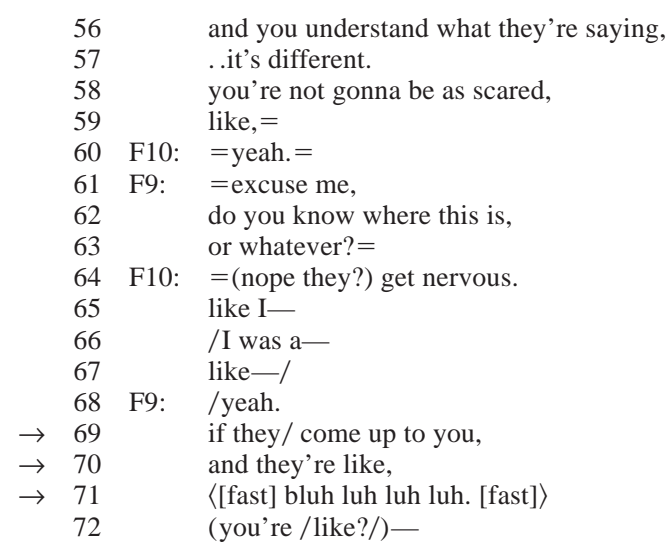

Once F9 has affirmed the truth of F10's position on incomprehensible foreigners with this scenario (69-71), F10 begins to participate once again in the now collaborative performance. Her renewed performance (ex. 16) is clearly more an expression of ideological solidarity with F9 than an explanatory answer to an interview question. F10 repeats F9's you're like as she resets the scene (73), but then immediately responds to F9's performed imitation by laughing and agreeing with its accuracy (75). Finally, she uses the opportunity gained by her having taken the floor loudly and retells the story once more, this time with highly exaggerated constructed thought, during which she offers her most extreme transformation of the nonnative English speaker (lines 83-84):

(16) Complete version III

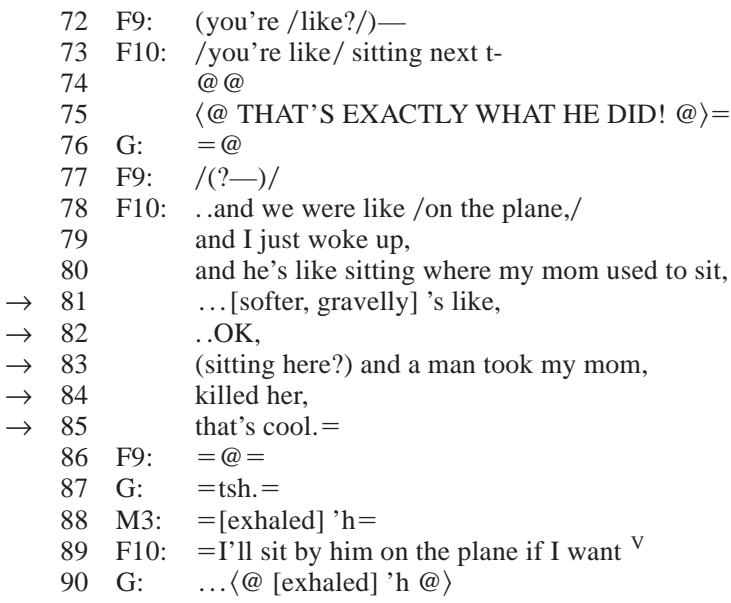

Interestingly, in this final version she does not mention that he talks to her. Rather, she replaces his speech with her thought $(81-85,89)$ and then ends the performance with a focus on her own fear, however ironically expressed. 
Each successive rendition of this story is a repetition of the essential narrative events and ideological propositions of the first version with a performed transformation of one or more of its elements. Because performances can be recontextualized, the ideological premises inscribed in them can easily and quickly become increasingly outlandish. However, at the same time, some of those premises become increasingly fixed: Foreigners are scary. People with accents are incomprehensible. Stories about scary, incomprehensible foreigners are performable.

Herein lies a paradox: Because performance carries the potential for dramatic transformations, the very fixity that indexes an ideological core, providing speakers with the regularized linguistic resources they need to create unique performances, can simultaneously serve as a springboard for constructing extreme, peripheral positions - positions that were not so clearly shared in this case by F10's interlocutors. Performance's capacity for recontextualization makes performed ideological discourse all the more susceptible to multiple interpretations and multiple voicings.

The notion of recontextualization (relation 5) is thus clearly related to the collective nature of performances (relation 4). To the extent that performances provide opportunities for collaboration in the making of ideological meaning, they can also create new contexts in which to reframe ideological premises, which are often exaggerated as involvement in the performances builds (relation 3). Dialogic relations multiply as speakers move from interaction to interaction. This capacity for recontextualization plays a critical role, then, in the social construction of ideological models. It is central in mediating between discourse at the level of the single interactional encounter and at that of the entire discourse community. Such reframings, and thus extension of performances' lifespans, can occur with very long intervals between performances (Bauman 1986), or they can occur immediately, as in the multi-performance of the "murderer"-on-the-plane story.

A number of factors influence the potential for recontextualizing that a given performance may have, including the aesthetic skill of a particular performer and the "sound bite" effect of an especially concise performance. Equally important, or perhaps more important, is the ideological salience of the performance. Buttny \& Williams 2000 refer to this salience as a particular resonance of others' words. In their analysis of students' use of repeated themes and structures, particularly surrounding the notion of "respect," they suggest not only that certain words had a performative power that led students to repeat them frequently, but also that the argument the students heard on a video gave them powerful and memorable ways of articulating their ideas about race. Such resonance is particularly available with dominant ideologies because they are so closely associated with performable linguistic forms. The incomprehensible accent, for example, is so readily available as a trope that it is highly likely to be performed and reperformed when speakers provide even the smallest space for such performances. Indeed, the dominant ideology contains a number of narrative prototypes, such as the angry immigrant or the first encounter with an international instructor, that are particularly suscepti- 
ble to recontextualizing. We thus see a unifying force in language, one that encourages the reiteration of certain ideological positions, partly because of their inseparable relation to pre-patterned, performable linguistic structures and partly because of an ideological context that accepts the truth of those positions.

S UMMARY AND IMPLICATIONS

Performance plays a critical role in the joint construction of linguistic as well as other ideologies, while the relative stability of ideological discourse plays a role in determining the form that performances take. The co-constitutive nature of the performance/ideology relationship has been further delineated into the following five relations:

1. Performances index existing ideological models.

2. The relatively limited set of discourse patterns (metaphors, themes, arguments, etc.) entailed by a given ideology are readily available, and are drawn upon, as resources for aesthetic displays.

3. The framing of talk as performance opens up a discursive space for constructing ideological extremes and stereotypes and, more important, for momentarily rendering them acceptable.

4. The collaboration that performances invite creates opportunities for the proliferation of ideological extremes.

5. Performances' capacity for recontextualization allows ideological premises to be shaped by greater numbers of speakers and therefore to be subjected to multiple transformations.

Although ideological models must exist in some relatively fixed form in order to provide content for performances, those models are further transformed in the course of new performances. Those transformations may be extreme exaggerations or merely a simplifying of core premises of the ideological model, as in F10's claim I couldn't understand him. Like period. With such statements, a speaker has the power to reify hegemonic notions in such a way that, particularly within the "sanctuary" of a performance frame, those notions go unchallenged. If F10 says the man was incomprehensible, the man was incomprehensible. Because the trope of the incomprehensible accent is so readily available in public discourse, any speaker, even one who might express a competing position moments later, is able to draw on that trope and even exaggerate it with impunity. Not only does no one question the truth of an Other's lack of proficiency, despite evidence to the contrary, but that truth becomes more firmly embedded in a collectively understood reality.

This is not to suggest that counter-discourses are not available for performing. Indeed, the existence of competing ideologies provides speakers with a wide range of discursive forms with which they can display their aesthetic skill. In my own data, some participants did create dramatic performances of anti-racist or multilingualist positions, such as an emphatic, jointly constructed complaint that 
the student who said Chinaman was living in the Stone Age. Performances of counter-discourses are opportunities to express shared resistance, but even for participants in such resistance, the patterns and tropes associated with less dominant ideological models are not as salient as those associated with dominant ones. Indeed, the students in this study who expressed more inclusive positions were still more likely to construct performances around monolingualist rather than multilingualist models. The very fixity of discourse patterns that often indicates a dominant ideological position is the same fixity that provides a resource for aesthetic transformation. Thus, entrance into a dominant discourse opens up possibilities for speakers to begin a performance. As we have seen in the discussion of collaboration, performances provide a space for tightening ideological cohesiveness among participants. The scales are tipped, then, in favor of dominant ideologies, which are more firmly established as regularized patterns in public and everyday discourse.

Performances such as the "murderer"-on-the-plane story allow extreme, exaggerated representations of marginalized groups in particular to be remembered and reanimated in other contexts. Moreover, the performance frame itself, because of speakers' and listeners' heightened concern for drama, protects these ideological models from conscious critical examination. The combination of these forces - reification, exaggeration, and exemption from critique - has serious implications. First, they prevent performers and audiences from addressing, or even noticing, contradictions between others' behavior and how that behavior is represented in performances. Gal \& Irvine 1995 call this semiotic process ERASURE, whereby facts inconsistent with an ideological model are rendered invisible. The erasure of certain sociolinguistic phenomena and of competing models, then, becomes heightened during performative talk. Second, when exaggerated, transformed representations become reified, the opportunity to critique them not only by participants within a given interaction but by the community at large is significantly diminished. The potential for recontextualizing performances or parts of performances makes this process even more rapid. Finally, these ideologies produce discourses of the Other that intersect with material practices of exclusion. On a small scale, such an intersection may result in, for example, pronunciation courses required of all nonnative English-speaking students. On a much larger scale, we have already seen the rise of monolingualist language policies in the United States and elsewhere (Silverstein 1987, Blommaert \& Verschueren 1992, Gal \& Irvine 1995, Crawford 2000, Hoffman 2003). The social and linguistic order underlying these practices provides the discursive fodder for performances, which in turn construct a reality that is more likely to confirm than to challenge that order.

\section{NOTES}

* I wish to thank Jane Hill, Kimberly Jones, Douglas Adamson, and two anonymous reviewers for their perceptive and helpful comments on earlier versions of this article and on the dissertation from which it comes. I also greatly appreciate Jane McGary's careful editing. 
${ }^{1}$ I have used single quotation marks to distinguish concepts, which may be expressed in a number of ways, from the actual expressions of those concepts, marked with double quotation marks. In-text excerpts from interview data are marked with italics.

${ }^{2}$ I have adapted transcription methods from Edwards \& Lampert 1993 and have divided transcripts into intonation units (Chafe 1993) to highlight rhythms and repetitions of intonational contours, which constitute performative strategies. Other transcription conventions are as follows:

:
$=$
..
$\ldots$
$/$ text/
$/ /$ text $/ /$
téxt
te-
text-
$\cdot$
$?$
$?$
v

$!$
TEXT
[text]
(text?)
@
$\langle @$ text @ $\rangle$
$\langle[$ fast] text [fast] $\rangle$
?

elongated sound

latching (no pause between turns by different speakers)

short pause (under one-half second)

longer pause

overlapping speech

overlap-used to distinguish successive overlapping utterances

stressed syllable or word

truncated word

truncated intonation unit

sentence-final (low, falling) intonation

continuing turn but end of intonation unit

question intonation

rising intonation on declarative utterances (includes the common

rise on "mhm" and other backchannel cues)

forceful, exclamatory intonational contour

loud or emphatic stress

researcher observations or descriptions of extralinguistic factors

best guess about what was said

one pulse of laughter

laughing or laughing quality throughout an utterance

$\langle[$ fast] text [fast] $]$

characteristic in brackets continues throughout the utterance

glottal stop (when it appears anywhere other than in conventional contractions and possessives)

${ }^{3}$ I wish to thank an anonymous reviewer for this particularly apt expression.

${ }^{4}$ The term "performative" builds upon Austin's (1975) notion of performativity as the enactive function of speech, but focuses specifically on the aesthetics of talk. "Performative talk," then, refers to speech that draws attention to the poetics of its form.

${ }^{5}$ The potential for a gendered reading of F10's fear of victimization by a male antagonist cannot be ignored. Indeed, such a reading could conceivably include an analysis of the relation between ideologies of race, to which the ideology of nativeness is more directly linked, and ideologies of gender. However, at the moment of the narrative event, rather than the narrated event, the speaker herself highlights his lack of comprehensibility as a nonnative, foreign English speaker, and thus the present analysis focuses only on the role the ideology of nativeness plays in this interaction.

${ }^{6}$ Part of this ideology is the notion that the use of English in the United States is NOT a tool of linguistic exclusion. It is not only not considered rude for people to speak English in the presence of those who do not understand it, but the non-English speaker's lack of comprehension is also considered a moral failure.

${ }^{7}$ This accounts for the common complaint that "political correctness" has ruined America's sense of humor. That is, many people justify offensive jokes using the sanction of the performance frame: If we are joking, anything goes.

${ }^{8}$ Interestingly, he could have said a Japanese, a Chinese, a Portuguese, but he did not. This choice can be partly explained by the fact that he began with students from Germany. However, it may also be that the combined social and semantic constraints against using terms for certain ethnic, national, or racial attributes as singular nouns (compare the effects of black as an adjective and a black as a noun) are tighter than the social constraints against using certain dated, derogatory ethnic terms.

${ }^{9}$ We can probably assume that this man was Arab, given that F10 mentions flying back over from Saudi Arabia and then mentions the man's name (Ali? Dali?) without mentioning his ethnicity. Were he to have had a "foreign" name and be from somewhere other than the Middle East would have rendered a non-Arab ethnicity in this context marked. 
${ }^{10}$ Such a disregard for other languages is part of the ideology of nativeness and therefore becomes available as an opportunity to perform (Shuck 2001).

${ }^{11}$ Because of the wavelike shifts in performative intensity that might comprise any performance, I am identifying the combination of all three - or, if we include F9's contribution, four - miniperformances as constituting a single performance.

\section{REFERENCES}

American Civil Liberties Union (2002). ACLU sues four major airlines over discrimination against passengers. http://www.aclu.org/news/2002/n060402b.html.

Austin, J. L. (1975). How to do things with words. 2nd ed. Cambridge, MA: Harvard University Press. Bakhtin, Mikhail M. (1981). The dialogic imagination, Michael Holquist (ed.), Caryl Emerson \& Michael Holquist (trans.). Austin: University of Texas Press.

Bateson, Gregory (1972). Steps to an ecology of mind. New York: Ballantine.

Bauman, Richard (1977). Verbal art as performance. Prospect Heights, IL: Waveland. (1986). Story, performance, and event: Contextual studies of oral narrative. Cambridge: Cambridge University Press. (1992). Icelandic legends: the traditionalization of genre. In Alessandro Duranti \& Charles Goodwin (eds.), Rethinking context: Language as an interactive phenomenon, 125-45. Cambridge: Cambridge University Press. , \& Briggs, Charles (1990). Poetics and performance as critical perspectives on language and social life. Annual Review of Anthropology 19:59-88.

Becker, Alton L. (1979). Text-building, epistemology, and aesthetics in Javanese shadow theatre. In A. L. Becker \& A. Yengoyan (eds.), The imagination of reality, 211-43. Norwood, NJ: Ablex. (1984). The linguistics of particularity: Interpreting superordination in a Javanese text. Proceedings of the Tenth Annual Meeting of the Berkeley Linguistics Society, 425-36. Berkeley: University of California, Berkeley.

Blommaert, Jan, \& Verschueren, Jef (1992). The role of language in European nationalist ideologies. Pragmatics 2:355-75.

Bowen, J. R. (1989). Poetic duels and political change in the Gayo highlands of Sumatra. American Anthropologist 91:25-40.

Briggs, Charles (1988). Competence as performance: The creativity of tradition in Mexicano verbal art. Philadelphia: University of Pennsylvania Press.

(1996). Introduction. In C. Briggs (ed.), Disorderly discourse: Narrative, conflict, and inequality, 3-40. New York: Oxford University Press.

(1998). "You're a liar-you're just like a woman!" Constructing dominant ideologies of language in Warao men's gossip. In Bambi Schieffelin et al. (eds.), Language ideologies: Practice and theory, 229-55. New York: Oxford University Press.

Buttny, Richard, \& Williams, Princess (2000). Demanding respect: The uses of reported speech in discursive constructions of interracial contact. Discourse and Society 11:109-33.

CBS News (2002). Feds detain hundreds of immigrants. http://www.cbsnews.com/stories/2002/ 12/19/attack/main533627.shtml.

Chafe, Wallace (1993). Prosodic and functional units of language. In Edwards \& Lampert, 33-43.

Crawford, James (2000). At war with diversity: U.S. language policy in an age of anxiety. Clevedon, England: Multilingual Matters.

Edwards, Jane, \& Lampert, Martin (1993) (eds.). Talking data: Transcription and coding in discourse and research. Hillsdale, NJ: Lawrence Erlbaum Associates.

Erickson, Frederick (1992). They know all the lines: Rhythmic organization and contextualization in a conversational listing routine. In Peter Auer \& Aldo Di Luzio (eds.), The contextualization of language, 365-97. Amsterdam \& Philadelphia: John Benjamins.

Gal, Susan, \& Irvine, Judith (1995). The boundaries of languages and disciplines: How ideologies construct difference. Social Research 62:967-1001.

Goffman, Erving (1974). Frame analysis: Essays on the organization of experience. New York: Harper \& Row.

Grice, H. P. (1975). Logic and conversation. In P. Cole and J. L. Morgan (eds.), Syntax and semantics, vol. 3: Speech acts, 113-27. New York: Academic Press. 
Gumperz, John (1992). Contextualization and understanding. In Alessandro Duranti \& Charles Goodwin (eds.), Rethinking context: Language as an interactive phenomenon, 229-52. Cambridge: Cambridge University Press.

Haviland, John (1996). "We want to borrow your mouth": Tzotzil marital squabbles. In Charles Briggs (ed.), Disorderly discourse: Narrative, conflict, and inequality, 158-203. New York: Oxford University Press.

Hill, Jane (1992). "Today there is no respect": Nostalgia, "respect" and oppositional discourse in Mexicano (Nahuatl) language ideology. Pragmatics 2:263-80.

Hoffman, Wayne (2003). Group will try again to make English Idaho's language. Idaho Statesman, 24 January 2003, 4 Local.

Inda, Jonathan Xavier (2000). Foreign bodies: Migrants, parasites, and the pathological nation. Discourse 22:46-62.

Jaret, Charles (1999). Troubled by newcomers: Anti-immigrant attitudes and action during two eras of mass immigration to the United States. Journal of American Ethnic History 18:9-39.

Kroskrity, Paul (1992). Arizona Tewa kiva speech as a manifestation of linguistic ideology. Pragmatics 2:297-309.

(1999). Language ideologies, language shift, and the imagination of a Western Mono community: The recontextualization of a Coyote story. In Jef Verschueren (ed.), Language and ideology: Selected papers from the 6th International Pragmatics Conference, Vol. 1, 270-89. Antwerp: International Pragmatics Association.

Limón, José (1982). History, Chicano joking, and the varieties of higher education: tradition and performance as critical symbolic action. Journal of the Folklore Institute 19:141-66.

Lippi-Green, Rosina (1997). English with an accent: Language, ideology, and discrimination in the United States. London: Routledge.

Müller, Klaus (1992). Theatrical moments. In Peter Auer \& Aldo di Luzio, (eds.), The contextualization of language, 199-231. Amsterdam \& Philadelphia: John Benjamins.

Ochs, Elinor (1990). Indexicality and socialization. In J. W. Stigler et al. (eds.), Cultural psychology, 287-308. Cambridge: Cambridge University Press.

Philips, Susan U. (1983). The invisible culture: Communication in classroom and community on the Warm Springs Indian Reservation. New York: Longman.

Shaheen, Jack (2001). Reel bad Arabs: How Hollywood vilifies a people. Northampton, MA: Interlink.

Sherzer, Joel (1987). A discourse-centered approach to language and culture. American Anthropologist 89:295-309.

Shuck, Gail (2001). Imagining the native speaker: The poetics of complaint in university student discourse. Dissertation, University of Arizona.

Silverstein, Michael (1979). Language structure and linguistic ideology. In P. Clyne et al. (eds.), The elements: A parasession on linguistic units and levels, 193-247. Chicago: Chicago Linguistic Society.

(1987). Monoglot "standard" in America: Standardization and metaphors of linguistic hegemony. (Working Papers and Proceedings of the Center for Psychosocial Studies, 13.) Chicago: Center for Psychosocial Studies. Reprinted in Donald Brenneis \& Ronald Macaulay (eds.), The matrix of language, 284-306. Boulder: Westview.

Tannen, Deborah (1979). What's in a frame? Surface evidence for underlying expectations. In Roy Freedle (ed.), New directions in discourse processing, 137-81. Norwood, NJ: Ablex.

(1989). Talking voices: Repetition, dialogue, and imagery in conversational discourse. Cambridge: Cambridge University Press.

, \& Wallat, Cynthia (1993). Interactive frames and knowledge schemas in interaction: Examples from a medical examination/interview. In Deborah Tannen (ed.), Framing in discourse, 57-76.

Wilce, James (1998). Eloquence in trouble: The poetics and politics of complaint in rural Bangladesh. Oxford: Oxford University Press.

Woolard, Kathryn (1989). Sentences in the language prison: the rhetorical structuring of an American language policy debate. American Ethnologist 16:268-78.

Yankah, Kwesi (1985). Risks in verbal art performance. Journal of Folklore Research 22:133-53.

(Received 2 July 2002, accepted 13 October 2002, final revision received 30 April 2003) 